From the Department of Pathology, University Medical Centre, St Radboud, Nijmegen; Departments of Surgery and Clinical Oncology, Leiden University Medical Centre, Leiden, the Netherlands; Academic Unit of Pathology, University of Leeds, United Kingdom. The Pathology Review Committee and the Cooperative Clinical Investigators of the Dutch Colorectal Cancer Group.

Submitted May 31, 2005; accepted September 20, 2005

Authors' disclosures of potential conflicts of interest are found at the end of this article.

Address reprint requests to Phil Quirke, MD, FRCPath, Academic Unit of Pathology, University of Leeds, Leeds LS22 4HT, United Kingdom; e-mail: patpq@leeds.ac.uk.

(C) 2005 by American Society of Clinical Oncology

0732-183X/05/2336-9257/\$20.00

DOI: 10.1200/JCO.2005.02.9231

\title{
Low Rectal Cancer: A Call for a Change of Approach in Abdominoperineal Resection
}

Iris D. Nagtegaal, Cornelius J.H. van de Velde, Corrie A.M. Marijnen, Jan H.J.M. van Krieken, and Philip Quirke

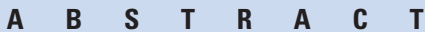

\section{Purpose}

Despite the major improvements that have been made due to total mesorectal excision (TME), low rectal cancer still remains a challenge.

\section{Methods}

By investigating a prospective randomized rectal cancer trial in which surgeons had undergone training in TME the factors responsible for the poor outcome were determined and a new method for assessing the quality of surgery was tested.

\section{Results}

Survival differed greatly between abdominoperineal resection (APR) and anterior resection (AR; $38.5 \% \vee 57.6 \%, P=.008$ ). Low rectal carcinomas have a higher frequency of circumferential margin involvement $(26.5 \%$ v $12.6 \%, P<.001)$. More positive margins were present in the patients operated with APR (30.4\%) compared to AR $(10.7 \%, P=.002)$. Furthermore, more perforations were present in these specimens $(13.7 \% \vee 2.5 \%, P<.001)$. The plane of resection lies within the sphincteric muscle, the submucosa or lumen in more than $1 / 3$ of the APR cases, and in the remainder lay on the sphincteric muscles.

\section{Conclusion}

We systematically described and investigated the pathologic properties of low rectal cancer in general, and APR in particular, in a prospective randomized trial including surgeons who had been trained in TME. The poor prognosis of the patients with an APR is ascribed to the resection plane of the operation leading to a high frequency of margin involvement by tumor and perforation with this current surgical technique. The clinical results of this operation could be greatly improved by adopting different surgical techniques and possibly greater use of radiochemotherapy.

\section{J Clin Oncol 23:9257-9264. (C) 2005 by American Society of Clinical Oncology}

\section{INTRODUCTION}

Total mesorectal excision has played a major role in reducing the rates of local recurrence and improving survival in rectal cancer. ${ }^{1-3}$ One reason for this is the higher frequency of complete resection of the tumor together with its lymphatic and venous drainage that is achieved by complete removal of the mesorectum $^{4,5}$ Worldwide, standard local recurrence rates of $25 \%$ to $50 \%$ have dramatically fallen and survival has improved. While survival for patients with very low rectal cancer has im- proved, it has not done so to the same degree as mid- and upper-rectal cancer. In a local study of 608 patients in Leeds, United Kingdom, ${ }^{6}$ we have previously shown that local recurrence is higher $(36.5 \% v 22.3 \%)$ and survival is lower $(52.3 \% v 65.8 \%)$ in patients undergoing abdominoperineal resection (APR) compared with anterior resection (AR). This was due to a higher rate of incomplete excision at the circumferential margin (CRM; 41\% v 12\%). The amount of tissue removed around the area of the tumor was less in APR than AR. Elsewhere, APR has been reported to have a higher local 
recurrence rate, a poorer survival, and a high perforation rate. ${ }^{7}$

Recently a more radical APR has been described by Holm where the low rectal cancer is removed from below using a wide perineal resection. ${ }^{6}$ This resembles the type of approach used by surgeons in the first part of the 20th century $^{8,9}$ that subsequently developed into the modern APR, in which the abdominal rather than the perineal approach dominates.

Important questions remain to be answered. Does AR of a low rectal cancer have an equivalent rate of CRM involvement compared to APR? Is a cure compromised by current techniques using AR for low rectal cancer?

In low rectal cancer, we wished to further explore the success of each type of operation, the frequency of circumferential margin involvement, the plane of the surgical resection as an indicator of the quality of resection, and the frequency of perforation. We also wished to identify the frequency of the wide perineal approach in a population. To do this, we chose the Dutch Radiotherapy (RT) Plus Total Mesorectal Excision (TME) Trial, a large multicenter trial in the Netherlands, in which 1,530 patients were included from January 1996 until December 1999. ${ }^{2}$ This prospectively randomized trial evaluated TME surgery with or without preoperative radiotherapy $(5 \times 5 \mathrm{~Gy})$. The pathology protocol had required photographs of the whole specimen and cross sectional slices of the tumor together with an assessment of the CRM. Local recurrence and survival data were available.

\section{METHODS}

\section{Study Population}

Patients were selected from the RT + TME trial, a large multicenter trial in the Netherlands, in which 1,530 patients were included from January 1996 until December 1999. ${ }^{2}$ This prospectively randomized trial evaluated TME surgery with or without preoperative radiotherapy $(5 \times 5 \mathrm{~Gy})$. Patients with clinicallyresectable adenocarcinoma of the rectum were included and were subsequently randomly assigned to either RT followed by TME or to TME alone. The radiotherapy, surgery, and pathology were standardized and subject to strict quality control. Follow-up of all patients was conducted according to the trial protocol. Outcome measures included local and distant recurrences. The study was approved by all institutional ethical committees. All patients gave written informed consent.

\section{Patient Selection}

For the current study we analyzed the data of the eligible Dutch patients in the trial as described earlier. ${ }^{10}$ The following patients were excluded from the analysis: no resection $(n=37)$, macroscopic resection locally not complete $(n=5)$, distant metastases at operation $(n=91)$, and no tumor at operation $(n=15)$. From the radiotherapy group: total dose not $25 \mathrm{~Gy}(\mathrm{n}=34)$, overall treatment time more than 10 days $(n=72)$, leaving 1,219 patients for the analysis. The median follow-up was 60.0 months.

\section{Preoperative Radiotherapy}

The patients assigned to preoperative radiotherapy received a total dose of $25 \mathrm{~Gy}$ in five fractions over 5 to 7 days. The irradiated volume included the primary tumor and the mesentery with vascular supply containing the perirectal, presacral, and the internal iliac nodes.

\section{Surgery}

All patients underwent surgery according to the principles of TME, as previously described. ${ }^{1}$ The main principles of this technique involve sharp dissection within the true pelvis around the integral mesentery under direct vision, envelopment of the entire midrectum, and preservation of the hypogastric plexus.

\section{Pathological Procedures}

Standardized pathology examination was performed in the pathology laboratories of the referring hospitals using the protocol of Quirke et al. ${ }^{5}$ Pathologists from the referral hospital recorded pathologic information of the resected tumor on a standard form for all patients. A pathology quality manager and a pathology review committee (PRC) were installed to ensure consistent quality of all pathology data and procedures. Special care was given to measurement of the CRM with an involved margin defined as tumor within $1 \mathrm{~mm}$ or less of the circumferential margin. ${ }^{4,5}$ Careful examination of the CRM was performed as well as investigation of tumor invasion of the bowel wall and surrounding tissue.

\section{Macroscopic Evaluation of the Resection Specimen}

The quality of the mesorectum was determined using pathology reports and scored using three grades (as has been described earlier ${ }^{11,12}$ ). The mesorectal grading system was designed for the United Kingdom Medical Research Council (MRC) CLASICC and CR07 trials. Additional grading of the levator area has been developed by Quirke for the United Kingdom National Cancer Research Institute Mercury study and the CORE phase II trial (Sanofi; Paris, France). The definitions are the same, but the descriptive term has been changed to describe the predominant plane of surgery rather than a subjective comment on quality. This is considered a more objective description of the quality of resection achieved without a value judgment by the pathologist.

\section{Mesorectum}

Muscularis propria plane (previously: poor/incomplete mesorectum). This plane has little bulk to the mesorectum with defects down onto muscularis propria and/or very irregular circumferential resection margin but still reaching to the muscularis propria.

Intramesorectal plane (previously: moderate/moderately complete mesorectum). This plane has moderate bulk to the mesorectum, but irregularity of the mesorectal surface. Moderate coning of the specimen is allowed. At no site is the muscularis propria visible.

Mesorectal plane (previously: good/complete mesorectum). This plane has intact mesorectum with only minor irregularities of a smooth mesorectal surface. No defect is deeper than $5 \mathrm{~mm}$. No coning towards the distal margin of the specimen. Smooth circumferential resection margin on slicing.

For AP resection, an additional classification system has been developed for the anal canal.

Intramuscular/submucosal plane (IMSM). This plane has perforation or missing areas of muscularis propria indicating entry into the muscular tube at this level (Fig 1A to C).

Sphincteric plane. This plane has CRM on the surface of the sphincteric muscular tube, but this is intact (Fig 1D). 


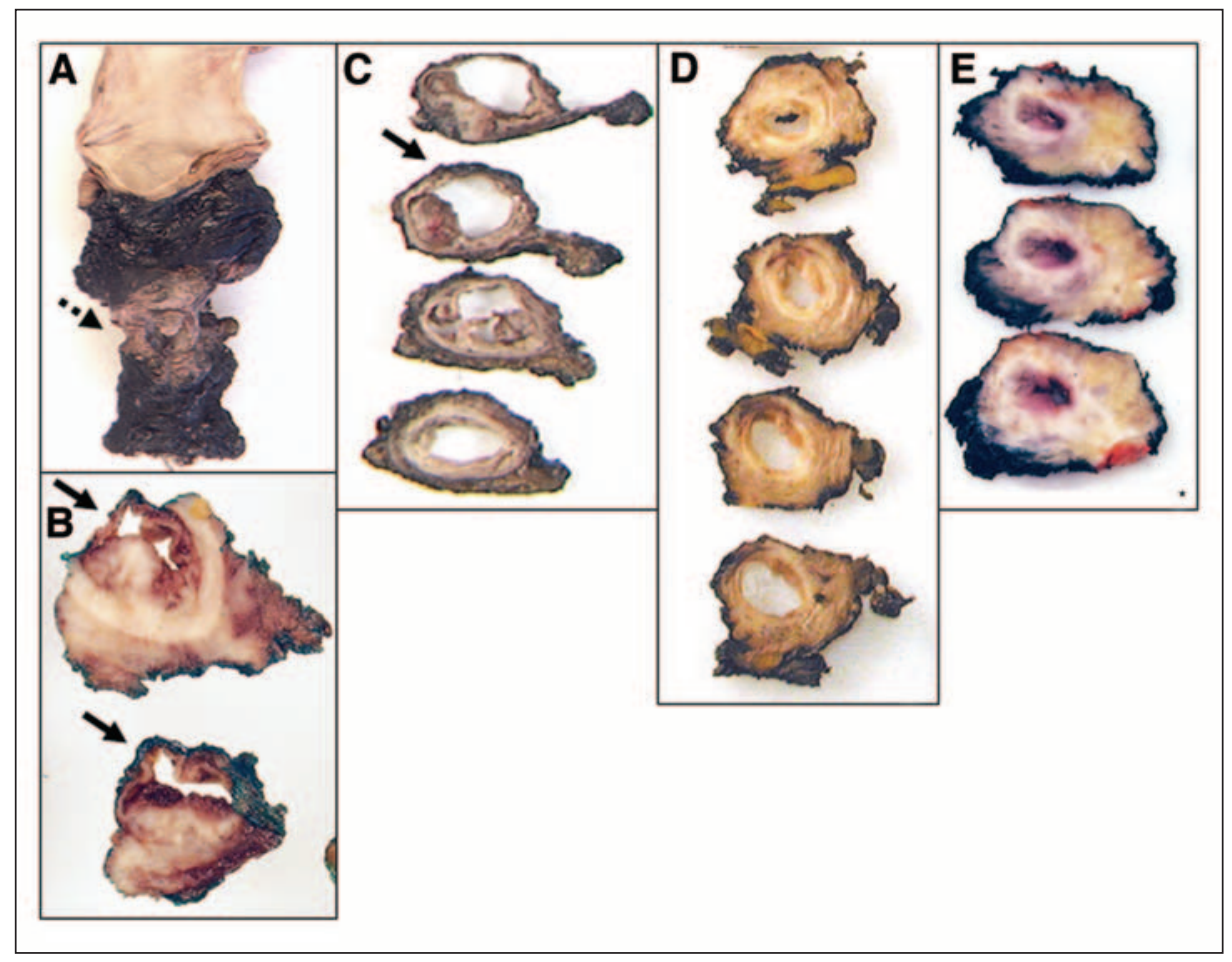

Fig 1. (A) Perforation through the sphincter muscles (arrow). (B and C) Surgical plane in the submucosa of the low rectum (arrows). (D) Standard plane on the sphincter muscles. (E) Cylindrical specimen from Mr. T. Holm Karolinska Hospital Stockholm Sweden. The asterisk is the site where the coccyx was removed from the specimen before dissection.

Outside levator plane. This plane has a cylindrical specimen with levators removed en bloc (Fig 1E).

\section{Evaluation of Quality of Resection}

PQ and IN discussed and selected appropriate photographs for each specimen, if either thought the photographs were inadequate then they were removed from the data set. Assessable photographs of AP resection specimens were present in 205 patients (55\%); these were analyzed by the two independent observers independently. An overall combined score was obtained by taking the poorest score.

\section{Data Collection and Statistics}

All case record forms were sent to the central data office at the surgery department of the Leiden University Medical Centre, Leiden, the Netherlands. The data were checked and entered in a database and analyzed with the SPSS package (SPSS 12.0 for Windows; SPSS Inc, Chicago, IL). Data were analyzed by IN. Relations between various parameters were analyzed using $\chi^{2}$ methods and Mann-Whitney's nonparametric testing procedures. A $P$ value of $\leq .05$ was considered statistically significant.

\section{RESULTS}

\section{Patient Characteristics}

Of the 1,219 assessable patients, 846 underwent an AR (69.4\%), 373 an APR (30.6\%). Tumors operated on with AR were, as could be expected, located at a greater distance from the anal verge. There was no difference between the randomization arms (Table 1) for both tumor localization and surgical technique. Since there was also no difference for tumor stage ${ }^{10}$ or margin involvement, ${ }^{13}$ both randomization groups were combined for further analyses.

Although there was no difference in tumor distribution between men and women, there were significantly more sphincter saving procedures performed in females $(P=.009)$. Between both surgical techniques, there were no differences in tumor type, grade, or stage; however, tumors operated on with APR were larger $(4.6 \vee 4.2 \mathrm{~cm}, P=.001)$.

\section{Involvement of Circumferential Margin}

Low rectal carcinomas (ie, $\leq 5 \mathrm{~cm}$ from the anal verge) had a higher frequency of circumferential margin involvement compared to tumors situated over $5 \mathrm{~cm}$ from the anal verge (Fig 2, Table 2; 26.5\% v 12.6\%, $P<.001$ ). While in all groups no positive margins were present in superficial carcinomas (T1), the percentage of positive margins in low T2 tumors $(11.4 \%)$ was almost as high as the total percentage of involvement in all higher tumors, and more than twice as high as the percentage involvement in higher T2 tumors $(P=.013)$. Positive CRMs in T2 tumors are a direct indicator of incomplete resection. ${ }^{11}$ In low node-negative tumors, a high percentage of cases showed a positive CRM $(16.0 \%)$. Tumor size was not correlated with margin involvement in the lower and middle rectum.

In the low rectal carcinomas ( 0 to $5 \mathrm{~cm})$ more positive margins were present in the patients operated by APR than $\operatorname{AR}(30.4 \% v 10.7 \%, P=.002)$. In the middle rectum (5-10 $\mathrm{cm}$ ) a higher frequency of positive CRMs were also present 


\begin{tabular}{|c|c|c|c|c|c|c|c|c|}
\hline & \multirow{2}{*}{$\begin{array}{l}\text { No. of } \\
\text { Patients }\end{array}$} & \multicolumn{4}{|c|}{ Tumor Height (\% of patients) } & \multicolumn{3}{|c|}{$\begin{array}{l}\text { Surgical Technique } \\
\text { (\% of patients) }\end{array}$} \\
\hline & & $0.0-4.9 \mathrm{~cm}$ & $5.0-9.9 \mathrm{~cm}$ & $\geq 10.0 \mathrm{~cm}$ & $P$ & APR & $A R$ & $P$ \\
\hline \multicolumn{9}{|l|}{ Randomization } \\
\hline TME & 658 & 32.7 & 39.2 & 28.1 & \multirow[t]{2}{*}{.40} & 31.2 & 68.8 & \multirow[t]{2}{*}{.65} \\
\hline $\mathrm{RT}+\mathrm{TME}$ & 561 & 29.3 & 42.4 & 28.3 & & 29.9 & 70.1 & \\
\hline \multicolumn{9}{|l|}{ Sex } \\
\hline Male & 778 & 32.5 & 39.1 & 28.4 & \multirow[t]{2}{*}{.25} & 33.2 & 66.8 & \multirow[t]{2}{*}{.009} \\
\hline Female & 436 & 28.7 & 43.6 & 27.8 & & 26.0 & 74.0 & \\
\hline \multicolumn{9}{|l|}{ Age } \\
\hline Mean, years & & 63.8 & 64.3 & 64.1 & .80 & 64.6 & 63.9 & .31 \\
\hline \multicolumn{9}{|l|}{ Tumor type } \\
\hline Adenocarcinoma & 1,092 & 29.7 & 41.6 & 28.8 & \multirow[t]{2}{*}{.009} & 30.0 & 70.0 & \multirow[t]{2}{*}{.19} \\
\hline Mucinous carcinoma & 120 & 43.3 & 33.3 & 23.3 & & 35.8 & 64.2 & \\
\hline \multicolumn{9}{|l|}{ Tumor grade } \\
\hline Good/moderate & 866 & 30.5 & 41.7 & 27.9 & \multirow[t]{2}{*}{.58} & 29.4 & 70.6 & \multirow[t]{2}{*}{.17} \\
\hline Poor/undifferentiated & 336 & 32.4 & 38.4 & 29.2 & & 33.5 & 66.5 & \\
\hline \multicolumn{9}{|l|}{ Tumor size } \\
\hline Mean, cm & & 4.5 & 4.2 & 4.4 & .09 & 4.6 & 4.2 & .001 \\
\hline \multicolumn{9}{|l|}{ Invasion depth } \\
\hline $\mathrm{T} 1$ & 65 & 24.6 & 44.6 & 30.8 & \multirow[t]{4}{*}{.27} & 21.5 & 78.5 & \multirow[t]{4}{*}{.21} \\
\hline T2 & 413 & 32.0 & 43.1 & 24.9 & & 32.4 & 67.6 & \\
\hline T3 & 693 & 31.2 & 39.8 & 29.0 & & 30.5 & 69.5 & \\
\hline $\mathrm{T} 4$ & 37 & 35.1 & 24.3 & 40.5 & & 32.4 & 67.6 & \\
\hline \multicolumn{9}{|l|}{ Nodal status } \\
\hline NO & 745 & 32.0 & 39.7 & 28.4 & \multirow[t]{3}{*}{.80} & 31.6 & 68.4 & \multirow[t]{3}{*}{.16} \\
\hline N1 & 260 & 28.4 & 43.5 & 28.1 & & 26.1 & 73.9 & \\
\hline N2 & 209 & 31.7 & 40.4 & 27.9 & & 33.3 & 66.7 & \\
\hline \multicolumn{9}{|l|}{ Surgical technique } \\
\hline APR & 373 & 82.3 & 16.8 & 0.8 & \multirow[t]{2}{*}{$<.001$} & & & \\
\hline$A R$ & 846 & 8.9 & 51.1 & 40.1 & & & & \\
\hline
\end{tabular}

Abbreviations: APR, abdominoperineal resection; AR, anterior resection; TME, total mesorectal excision; RT: short-term preoperative radiotherapy.

in this APR group of patients $(21.0 \% v 11.3 \%, P=.03)$. While in the high rectal carcinomas only three APR procedures were performed, two of those cases showed a positive margin, compared with $13.6 \%$ in the AR group. There was no difference in $\mathrm{T}$ stage, nor in tumor size between the two operation types. Tumor height in the lower and middle rectum was lower in the APRs, median values 2.0 and 5.0 $\mathrm{cm}$, respectively, compared to 4.0 and $7.0 \mathrm{~cm}$ in the ARs,

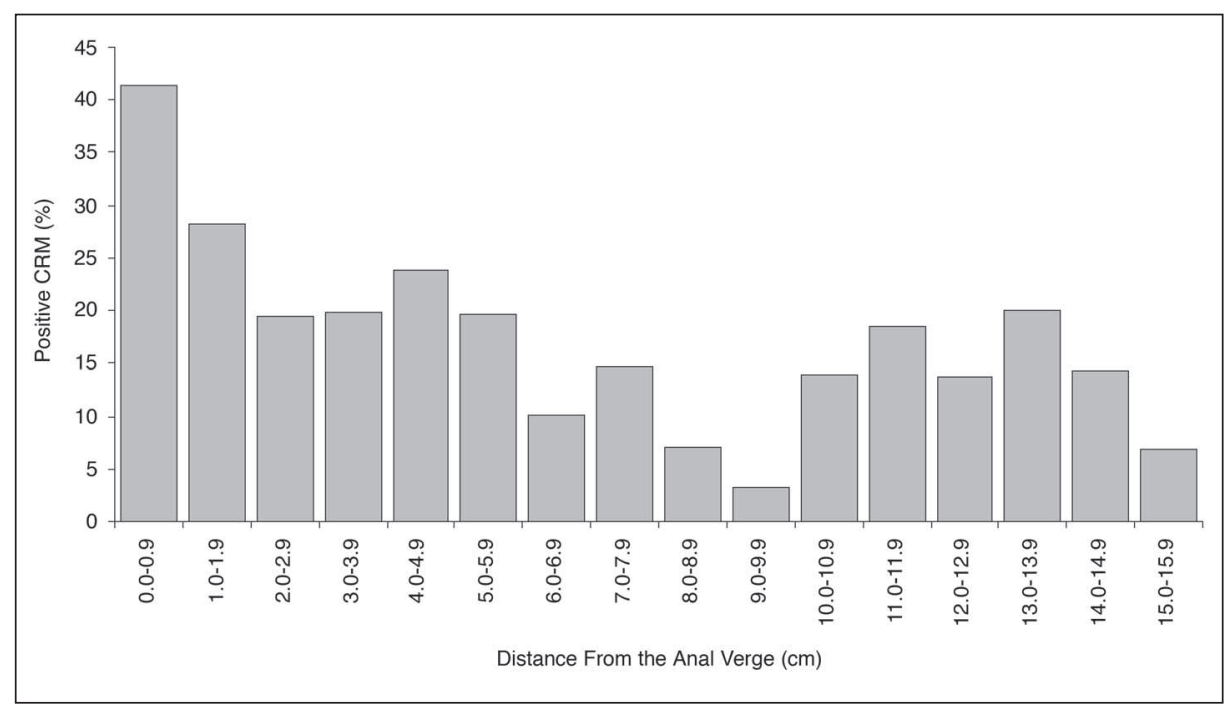

Fig 2. Relation of circumferential margin involvement with distance of the tumor from the anal verge. Percentages of positive circumferential margin are given. 
Table 2. Relation of Circumferential Margin Involvement (\% positive) With Tumor Height and Surgical Technique, Matched for Tumor Invasion and Lymph Node Status

\begin{tabular}{|c|c|c|c|c|c|c|c|c|}
\hline & \multirow{2}{*}{$\begin{array}{l}\text { Total \% } \\
\text { Positive }\end{array}$} & \multicolumn{4}{|c|}{ Tumor Height (\% of patients) } & \multicolumn{3}{|c|}{ Surgical Technique ( $\%$ of patients) } \\
\hline & & $0.0-4.9 \mathrm{~cm}$ & $5.0-9.9 \mathrm{~cm}$ & $\geq 10 \mathrm{~cm}$ & $P$ & APR & $A R$ & $P$ \\
\hline Total & 17.3 & 26.5 & 12.6 & 14.0 & $<.001$ & 29.0 & 12.2 & $<.001$ \\
\hline $\mathrm{T} 1$ & 0 & & & & & & & \\
\hline T2 & 6.3 & 11.4 & 4.5 & 2.9 & .013 & 11.9 & 3.6 & .001 \\
\hline T3 & 23.8 & 35.2 & 18.5 & 18.9 & $<.001$ & 39.9 & 16.7 & $<.001$ \\
\hline T4 & 51.4 & 69.2 & 33.3 & 46.7 & .09 & 58.3 & 48.0 & .24 \\
\hline No & 8.8 & 16.0 & 4.4 & 7.1 & $<.001$ & 17.8 & 4.7 & $<.001$ \\
\hline $\mathrm{N}+$ & 30.6 & 43.9 & 24.7 & 25.2 & $<.001$ & 47.8 & 23.7 & $<.001$ \\
\hline
\end{tabular}

Abbreviations: APR, abdominoperineal resection; $A R$, anterior resection.

$(P<.001)$. If cases are matched for distance from the anal verge and invasion depth (Table 3 ), APR operated patients still have a higher risk of a positive CRM. Due to small numbers the differences between the different surgical techniques are not significant.

There was no sex difference between the percentages of positive CRMs in the AR group (male 12.1\%, female $12.1 \%$, $P=.90)$. However, in the APR group more positive CRMs were present in the females $(39.5 \% v 24.3 \%, P=.003)$.

\section{Quality of the Anal Canal and the Mesorectum in APR Patients}

None of the cases were scored as outside the levator plane. The majority of the anal canals were scored as sphincteric, where the plane was on the sphincteric muscle $(\mathrm{n}=131,63.9 \%)$, whereas the remainder graded as IMSM or perforated $(\mathrm{n}=74,36.1 \%)$. The mesorectum was scored as in the mesorectal plane in $9.8 \%(n=20)$, intramesorectal plane in $57.1 \%(\mathrm{n}=117)$, and muscularis plane in $33.1 \%$ $(n=68)$. Between the scoring of the anal canal and the mesorectum was a correlation of 0.144 (Pearson's $R$ ), with a significance level of 0.039 , suggesting that there was a relationship between the plane of dissection in the mesorectum and in the anal canal.

\begin{tabular}{|c|c|c|c|c|}
\hline \multirow{2}{*}{$\begin{array}{l}\text { Tumor Height/ } \\
\text { Invasion Depth }\end{array}$} & \multicolumn{2}{|c|}{ APR } & \multicolumn{2}{|c|}{$A R$} \\
\hline & No./Total & $\%$ & No./ Total & $\%$ \\
\hline \multicolumn{5}{|l|}{$5 \mathrm{~cm}$} \\
\hline T2 & $0 / 14$ & 0 & $4 / 42$ & 9.5 \\
\hline T3 & $9 / 21$ & 42.9 & $9 / 31$ & 27.9 \\
\hline \multicolumn{5}{|l|}{$4 \mathrm{~cm}$} \\
\hline T2 & $2 / 14$ & 14.3 & $0 / 12$ & 0 \\
\hline T3 & $16 / 37$ & 43.2 & $3 / 13$ & 18.8 \\
\hline \multicolumn{5}{|l|}{$3 \mathrm{~cm}$} \\
\hline T2 & $1 / 27$ & 3.7 & $0 / 5$ & 0 \\
\hline Т3 & $11 / 27$ & 40.7 & $1 / 9$ & 11.1 \\
\hline
\end{tabular}

Abbreviations: APR, abdominoperineal resection; AR, anterior resection.

\section{Overall APR's Were More Likely to Have a Poorer Mesorectal Dissection Compared With AR}

In the anal canal, the specimens with an IMSM or sphincteric plane of resection showed an increased risk of a positive CRM, $33.8 \%$ and $27.2 \%$, which is comparable with the percentages in case of a muscularis plane in the mesorectum, ${ }^{11}$ suggesting that incomplete removal of anatomic structures in both areas compromises local tumor excision.

\section{Perforation Rates}

Analyses of photos and surgical and pathological reports revealed a total number of 72 perforations in the trial population $(\mathrm{n}=1,219,5.9 \%)$, the majority being present in the APR specimens $(51,13.7 \%$ of all APRs $v 21,2.5 \%$ of all ARs, $P<.001$; Table 4$)$. There was no difference in perforation rates between the random assignment arms.

In the APR group most perforations were present in patients with tumors located less than $5 \mathrm{~cm}$ above the anal verge (11.9\% of all APRs). In the AR group most perforations were present in patients with tumors between 5 and 10 $\mathrm{cm}(3.2 \%)$. Most perforations were present inside the tumor area (22 of 30, 42 cases unknown). In the APR group, most perforations were in the anal canal rather than in the mesorectum ( 24 of 31, 20 unknown); most of them were located posterior ( 22 of 34,17 unknown), whereas in the AR group only three of 10 cases were located posterior $(P=.051)$.

\section{Prognosis}

Local recurrence rates and survival rates were worse in patients with positive CRMs, independent of the surgical technique used (Table 5, Fig 3). Patients with a positive resection margin resulting from an APR procedure showed decreased survival rates compared to the AR group (38.5\% $v 57.6 \%, P=.008)$. Survival in patients with perforations in their specimens was poor, $44.5 \% \mathrm{v}$ $68.5 \%(P=.0005)$. 


\begin{tabular}{|c|c|c|c|c|c|c|c|}
\hline & \multicolumn{2}{|c|}{ Total } & \multicolumn{2}{|c|}{ APR } & \multicolumn{2}{|c|}{$\mathrm{AR}$} & \multirow[b]{2}{*}{$P$} \\
\hline & No. & $\%$ & No. & $\%$ & No. & $\%$ & \\
\hline All patients & 72 & 5.9 & 51 & 13.7 & 21 & 2.5 & $<0.001$ \\
\hline \multicolumn{8}{|l|}{ T stage } \\
\hline $\mathrm{T} 1$ & & & 1 & 7.1 & 0 & & 0.49 \\
\hline T2 & & & 18 & 12.8 & 4 & 1.5 & \\
\hline T3 & & & 30 & 14.2 & 16 & 3.3 & \\
\hline $\mathrm{T} 4$ & & & 2 & 16.7 & 1 & 4.0 & \\
\hline \multicolumn{8}{|l|}{ Tumor size* } \\
\hline Median & & & & & & & 0.68 \\
\hline Range & & & & & & & \\
\hline \multicolumn{8}{|c|}{ Tumor height† } \\
\hline$<5 \mathrm{~cm}$ & & & 37 & 11.9 & 0 & & $<0.001$ \\
\hline $5-9.9 \mathrm{~cm}$ & & & 12 & 20.0 & 14 & 3.2 & \\
\hline$>10 \mathrm{~cm}$ & & & & & 7 & 2.1 & \\
\hline Median & & & & & & & $<0.001$ \\
\hline Range & & & & & & & \\
\hline $\begin{array}{l}\text { NOTE. Perce } \\
\text { Abbreviation } \\
\text { "Missing val } \\
\text { †Missing val }\end{array}$ & $\begin{array}{l}\text { re giv } \\
\text { operir }\end{array}$ & $A R$, & tion. & & & & \\
\hline
\end{tabular}

\section{DISCUSSION}

Total mesorectal excision has dramatically changed the local recurrence rates and survival of middle $(5$ to $10 \mathrm{~cm})$ and upper rectal cancer (10 to $15 \mathrm{~cm}$ ). However, low rectal cancer ( 0 to $5 \mathrm{~cm}$ of the anal verge) continues to have a disappointing outcome with $10.0 \%$ local recurrence (at 2 years follow-up) in our trial. ${ }^{2}$ Despite the adoption of total mesorectal excision with radiotherapy, the removal of tumor in the low rectum continues to present many challenges. The mesorectum tapers above the levators and stops at the most proximal insertion point of the sphincters. The standard total mesorectal excision for an abdominoperineal resection follows the mesorectal fascia onto the sphincters and with the predominantly abdominal approach, the most important area of resection, which around the tumor itself, is located at the floor of the pelvis where good visualization and access are limited. These difficulties lead to a high intraoperative perforation rate in low rectal cancer and a high level of circumferential margin involvement.

This is the first report of a systematic attempt to describe and investigate the pathological properties of low rectal cancers in general and APRs in particular within a major clinical trial. This study confirms the higher rate of CRM involvement, higher perforation rates, higher local recurrence rates, and poorer survival of low rectal cancer. Importantly, it shows that higher rates of local recurrence apply to APR due to increased occurrence of positive CRM. This is probably due to the thinning of the mesorectum and the anatomy of the levators and sphincters at this site and the closeness of the CRM to the tumor as shown elsewhere. ${ }^{6}$

\begin{tabular}{|c|c|c|c|c|c|}
\hline \multirow[b]{2}{*}{ Operation Type } & \multirow[b]{2}{*}{$\begin{array}{l}\text { No. of } \\
\text { Patients }\end{array}$} & \multicolumn{2}{|c|}{ Local Recurrence } & \multicolumn{2}{|c|}{ 5-Year Survival } \\
\hline & & $\begin{array}{c}\% \text { of } \\
\text { Patients }\end{array}$ & $P$ & $\begin{array}{c}\% \text { of } \\
\text { Patients }\end{array}$ & $P$ \\
\hline \multicolumn{6}{|l|}{ APR } \\
\hline CRM- & 146 & 8.6 & .0002 & 72.0 & $<.0001$ \\
\hline CRM+ & 59 & 30.4 & & 38.5 & \\
\hline \multicolumn{6}{|l|}{ AR } \\
\hline CRM- & 392 & 9.2 & .07 & 70.7 & $<.05$ \\
\hline CRM+ & 61 & 17.1 & & 57.6 & \\
\hline
\end{tabular}




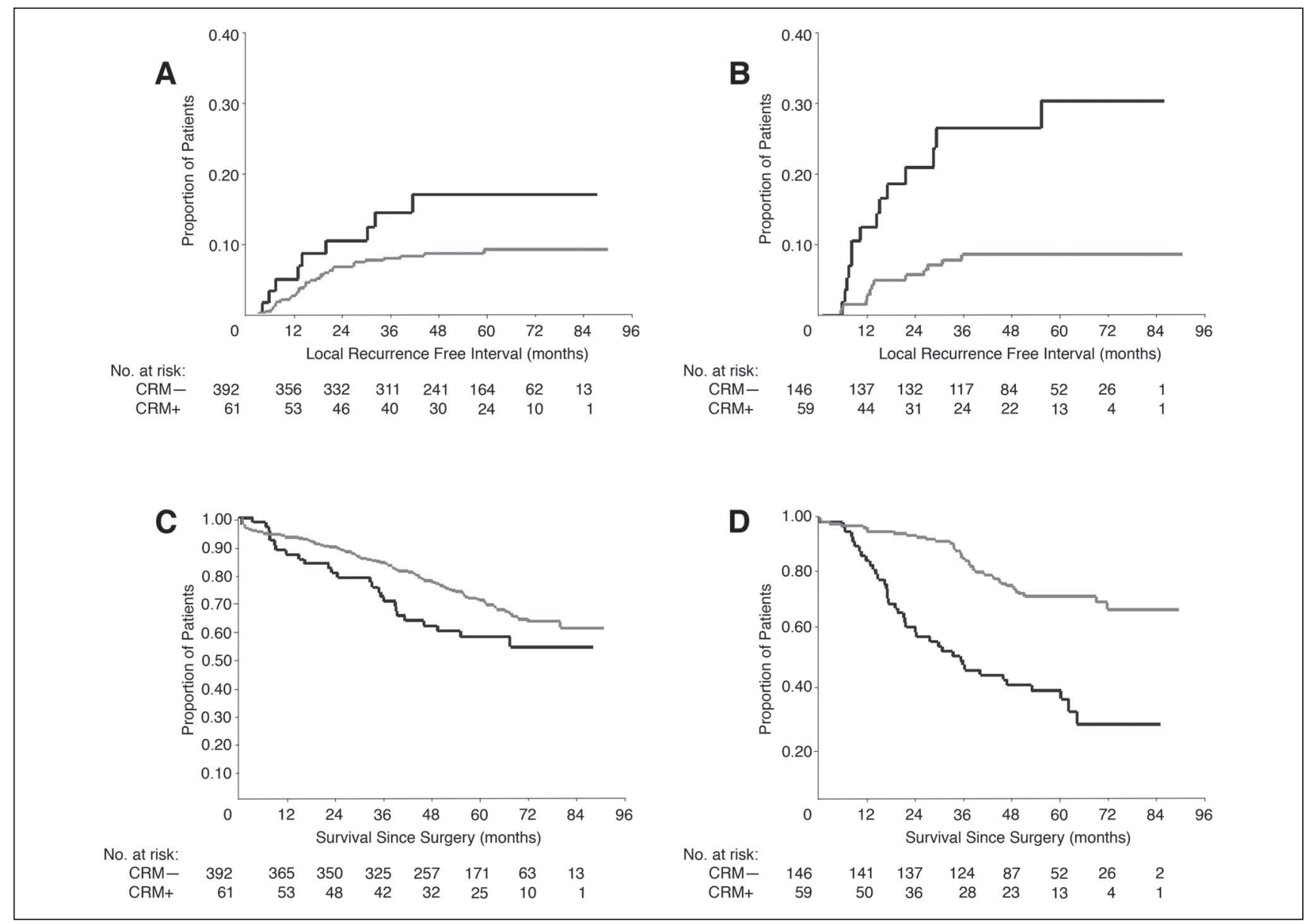

Fig 3. Prognosis in relation to surgical technique by circumferential margin (CRM) status. (A) Local recurrence rates in anterior resections, (B) Local recurrence rates in abdominoperineal resections, (C) Survival rates in anterior resections, (D) Survival rates in abdominoperineal resections. Only nonirradiated patients are analyzed. Black lines reflect positive margins, gray lines negative margins.

For the first time this study shows that in one third of cases, the plane of surgical excision lies within the mural sphincter muscle or the submucosa. In those cases with perforation, it is probable that the surgical plane has passed through all the layers of the bowel wall into the lumen or that the mechanical manipulation of removing the rectum has led to tearing of the rectum in areas where the plane of resection has entered into the muscle or submucosa.

Interestingly, the plane of surgical resection most frequently followed the mesorectal fascia and then passed over the surface or into the sphincter muscles providing little in the way of tissue to protect the surgical margin from direct spread of tumor circumferentially. The current APR is a nonradical operation and strong consideration should be given to the option of performing a more radical operation such as that described by others ${ }^{14}$ and pictured elsewhere. ${ }^{6}$ It could be argued that this wider surgical approach is the equivalent to total mesorectal excision in the upper- and mid-rectum, and the aim is to remove the entire rectum as a cylinder following the mesorectal plane from above and encompassing the levator plane from below. This form of more radical surgery may improve the current situation of high local recurrences and poorer survival, especially since neither radiotherapy ${ }^{13}$ nor adjuvant chemotherapy ${ }^{15}$ seem to be effective in patients with a positive resection margin.

We have demonstrated a high perforation rate in APR $(13.7 \%)$. This usually occurs in the low rectum either where the mesorectum thins or where it joins the sphincters or in the sphincters themselves. This is probably caused by intraoperative mechanical tension and manipulation of the specimen leading to tearing. The frequency of posterior perforation highlights the problem surgical access when approaching from above, which is technically difficult because of the natural curvature of the sacrum and coccyx. These difficulties could be avoided by the perineal approach to the low tumor. Good exposure is obtained and manipulation and pulling on the specimen is minimized. This approach should greatly reduce inadvertent entry into the wrong plane with perforations, which is associated with a greatly increased risk of local recurrence and death. ${ }^{16}$ 
From this study, it is apparent that the typical abdominoperineal resection performed in the Netherlands aims to follow the mesorectal fascia down onto the sphincters, thus reducing the cuff of uninvolved tissue lateral to the tumor and potentially reducing the frequency of clear surgical margins in low rectal cancer. This is also the standard approach in many surgical centers in the United Kingdom. From meetings at the Pelican Centre, Basingstoke, and PQ's personal discussions, it is apparent that there are Swedish centers that perform the cylindrical operation either removing the levators en bloc (Lars Pahlman, Uppsala, Sweden) or a wider operation field including ischio-rectal fat with or without the coccyx (Torborn Holm, Karolinska Hospital, Stockholm). The former operation has been described by Nicholls ${ }^{14}$ and other centers may perform the more radical operation. It is only by pathological assessments that the current frequency of the cylindrical operation may be established. We would suggest that surgical training in the perineal approach will reduce the frequency of CRM involvement and improve survival in low rectal cancer.

\section{Acknowledgment}

We thank the patients, surgeons, and pathologists of the Dutch TME/RT trial. Discussions and meetings at the Pelican center with Professor Heald, Brendan Moran, Torborn Holm, PhD, and Lars Pahlman, PhD, created many of the ideas tested in this study. PQ would like to thank Yorkshire Cancer Research and the National Health service MDT training initiative for personal support, and the Academic Oncologic Center Nijmegen for support for PQ to work in the Pathology Department, University of Nijmegen, the Netherlands.

\section{Authors' Disclosures of Potential Conflicts of Interest}

The authors indicated no potential conflicts of interest.

\section{REFERENCES}

1. Heald RJ, Husband EM, Ryall RD: The mesorectum in rectal cancer surgery-the clue to pelvic recurrence? Br J Surg 69:613-616, 1982

2. Kapiteijn E, Marijnen CAM, Nagtegaal ID, et al: Preoperative radiotherapy combined with total mesorectal excision for resectable rectal cancer. N Engl J Med 345:638-646, 2001

3. Wibe A, Moller B, Norstein J, et al: A national strategic change in treatment policy for rectal cancer-implementation of total mesorectal excision as routine treatment in Norway: A national audit. Dis Colon Rectum 45:857-866, 2002

4. Adam IJ, Mohamdee MO, Martin IG, et al: Role of circumferential margin involvement in the local recurrence of rectal cancer. Lancet 344:707-711, 1994

5. Quirke P, Durdey P, Dixon MF, et al: Local recurrence of rectal adenocarcinoma due to inadequate surgical resection: Histopathological study of lateral tumor spread and surgical excision. Lancet 2:996-999, 1986

6. Marr R, Birbeck KF, Garvican J, et al: The modern abdominoperineal excision-the next challenge after total mesorectal excision: A clinical and morphometric study. Ann Surg 242:7482, 2005

7. Wibe A, Syse A, Andersen E, et al: Oncological outcomes after total mesorectal excision for cure for cancer of the lower rectum: Anterior vs. abdominoperineal resection. Dis Colon Rectum 47:48-58, 2004

8. Miles WE: The radical abdominoperineal operation for cancer of the pelvic colon. BMJ 941-943, 1910

9. Miles WE: A method of performing abdominoperineal resection for carcinoma of the rectum and of the terminal portion of the pelvic colon. Lancet 1812-1813, 1908

10. Marijnen CAM, Nagtegaal ID, Klein Kranenbarg E, et al: No downstaging after shortterm preoperative radiotherapy in rectal cancer patients. J Clin Oncol 19:1976-1984, 2001
11. Nagtegaal ID, van de Velde CJH, van der Worp E, et al: Macroscopic evaluation of rectal cancer resection specimen: Clinical significance of the pathologist in quality control. J Clin Oncol 20:1729-1734, 2002

12. Maughan NJ, Quirke P: Modern management of colorectal cancer-a pathologist's view Scand J Surg 92:11-19, 2003

13. Marijnen CAM, Nagtegaal ID, Kapiteijn E, et al: Radiotherapy does not compensate for positive resection margins in rectal cancer patients. Int J Radiat Oncol Biol Phys 55:13111320, 2003

14. Nicholls RJ: Surgery for rectal carcinoma, in Nicholls RJ, Dozois RR, (eds): Surgery of the Colon and Rectum. London, United Kingdom, Churchill Livingston, 1997, pp 456-459

15. Taal BG, Van Tinteren $H$, Zoetmulder FA: Adjuvant 5FU plus levamisole in colonic or rectal cancer: Improved survival in stage II and III. Br J Cancer 85:1437-1443, 2001

16. Eriksen MT, Wibe A, Syse A, et al: Inadvertent perforation during rectal cancer resection in Norway. Br J Surg 91:210-216, 2004 